
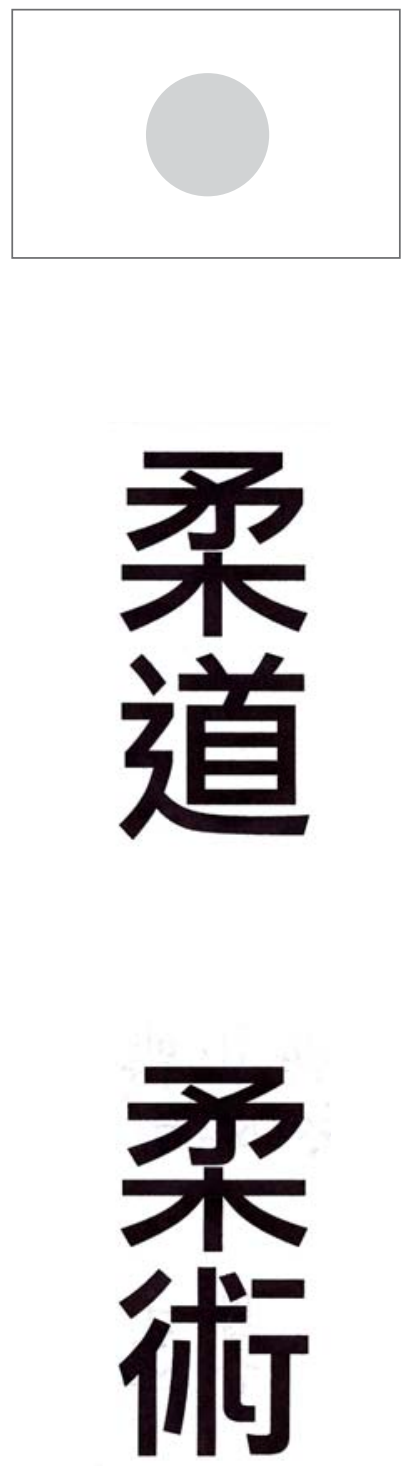

BAJO LA BANDERA JAPONESA ESTÁN LOS CARACTERES KANJI DE "JUDO" Y "JUJUTSU"

Fotografía DE GEORG

HACKENSCHMIDT

(1878-1968), EL PRIMER

Campeón Mundial

DE Lucha de los Pesos

PesAdOS RECONOCIDO EN 1905.

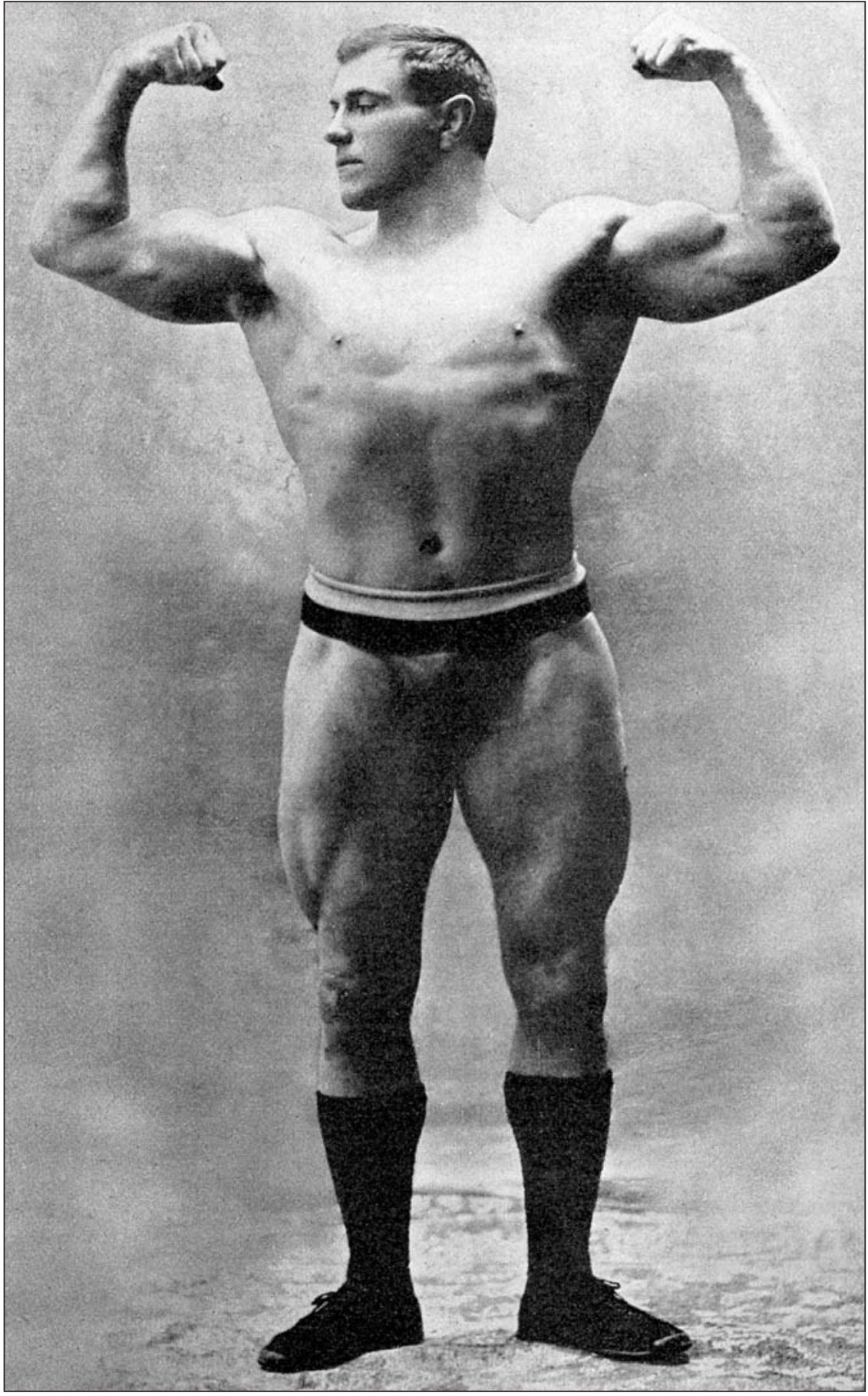

\section{Resumen}

Este ensayo analiza la inmigración japonesa-americana hacia el oeste de los Estados Unidos a través del prisma de los deportes, examinando específicamente una serie de enfrentamientos entre judokas y luchadores celebrados en California entre 1900 y 1920. La popularidad de estos enfrentamientos demuestra la compleja relación entre los japoneses-americanos y la cultura europeo-americana dominante en los estados occidentales durante este periodo. Esta complejidad se mostrará observando en primer lugar el modo en que las artes marciales están estrechamente relacionadas con la identidad étnica y nacional. La gran tradición existente en el mundo del espectáculo tanto en el judo como en la lucha condujo a la realización de diversos enfrentamientos que tuvieron un gran atractivo para los europeo-americanos de aquella época. Estos encuentros apelaban a un interés en la cultura japonesa, a un deseo de ver reforzados los estereotipos y a las tendencias nacionalistas durante una época de incertidumbre. 


\title{
El judo llega a CAlifornia Judo vs. Lucha en el oeste de los Estados Unidos, 1900-1920
}

\author{
Matt HLinak (ᄄe
}

\section{Introducción}

Este ensayo analiza la inmigración japonesa-americana hacia el oeste de los Estados Unidos a través del prisma de los deportes, examinando específicamente una serie de enfrentamientos entre judokas (practicantes de judo) japoneses-americanos y luchadores europeo-americanos celebrados en California entre 1900 y 1920. La popularidad de estos enfrentamientos demuestra la compleja relación entre los japoneses-americanos y la cultura europeo-americana dominante en los estados occidentales durante este periodo.

Esta complejidad se mostrará en primer lugar observando el modo en que las artes marciales están estrechamente relacionadas con la identidad étnica y nacional. Durante la última mitad del siglo XIX, las artes marciales occidentales del boxeo y de la lucha iniciaron una tendencia hacia la internacionalización deportiva que llevó a los primeros Juegos Olímpicos de la era moderna en 1896. El nacionalismo en el deporte le siguió casi inmediatamente. El estilo americano de "catch wrestling" [lucha libre americana] evolucionó a partir de estilos de lucha europeos modelados por las nociones decimonónicas del juego limpio y de artes viriles. Así, ha de señalarse que los primeros luchadores de catch perfeccionaban sus habilidades viajando con ferias por todo el país, cultivando un profundo sentido de la competición y de la masculinidad. A pesar de que la lucha profesional de hoy en día se ha convertido en un "teatro muscular", los luchadores de fin de siècle en el oeste de los Estados Unidos eran vistos como representantes de la ruda frontera masculina.

Del mismo modo, el judo tuvo una importante posición en la sociedad japonesa. A diferencia del catch, cuyos orígenes se remontan a diversos estilos populares de lucha europeos, el judo es un arte marcial japonés completamente indígena. En un esfuerzo por probar la efectividad de su arte, un puñado de hábiles judokas viajaron por todo el mundo desafiando (y a menudo derrotando) a luchadores locales; este éxito llevó a muchos japoneses a establecer similitudes entre el judo y el reciente ascenso de categoría de Japón en la política y economía globales. Del mismo modo, muchos occidentales vieron al misterioso arte del judo como la explicación de la aparentemente inexplicable victoria de Japón sobre Rusia en la guerra Ruso-Japonesa (1904-05). Los inmigrantes japoneses al oeste de los Estados Unidos trajeron consigo el judo, que ganó rápidamente popularidad entre los europeo-americanos.

Sin embargo, no todas las respuestas fueron positivas. Muchos occidentales simplemente desecharon el judo sobre la base de percepciones de inferioridad racial de los japoneses. Otros criticaron las tácticas del judo, encontrándolas inconsistentes respecto a los ideales en evolución de la deportividad occidental. Pero muchos europeo-americanos admiraron el modo en que un hábil judoka podía derrotar a un oponente notablemente más grande, e incluso unos pocos atribuyeron habilidades místicas o sobrenaturales a los atletas de origen japonés.

Tanto en el judo como en el catch existió una gran tradición en el mundo del espectáculo, así que el conflicto entre ambas formas de combate era inevitable. Los com- 


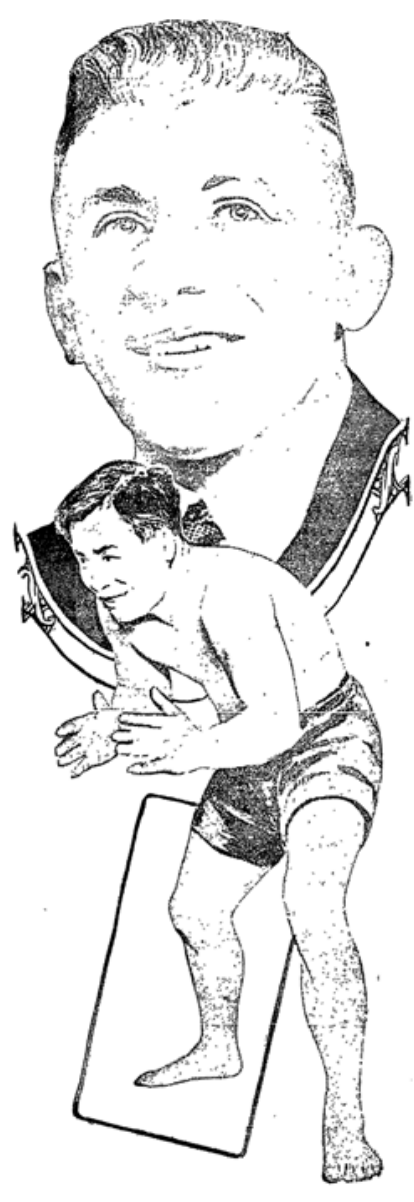

ANUNCIO DE UN COMBATE ENTRE AdOlPH “AD” SANTEl

(ARRIBA) Y EL EXPERTO EN JUJUTSU TARRO MiYAKI. Los Angeles Times (7 de abril de 1915).

bates entre judokas y luchadores casi siempre recaudaban más que aquellos que enfrentaban a dos competidores de un mismo estilo. Estos enfrentamientos también dieron lugar a la publicación de numerosos artículos en periódicos occidentales que comparaban ambas artes marciales.

Este ensayo concluirá discutiendo sobre las razones por las que estos combates eran tan atractivos para los europeo-americanos de los estados del oeste. Una razón fue el simple interés por la cultura japonesa. Pero los europeo-americanos también disfrutaron del modo en que estos enfrentamientos reforzaban los estereotipos sobre los japoneses-americanos. Por ejemplo, la habilidad de un judoka para derrotar a un oponente más grande enfatizaba la supuesta menor estatura física de los japoneses. Los judokas también eran retratados como excesivamente educados, en contraste con los rudos luchadores occidentales, lo cual reflejaba conceptos sobre la masculinidad muy contrastantes. Del mismo modo, algunas técnicas de judo, que eran ilegales en un combate de lucha, eran vistas como tácticas sucias, incoherentes con las nobles tradiciones deportivas. A los ojos de los europeo-americanos el judo, como los propios japoneses, era un concepto extranjero que alternativamente se ridiculizaba y temía.

Gran parte del interés europeo-americano en estos enfrentamientos se debía a la ansiedad que provocaba el contexto socio-político global. Los occidentales se sentían amenazados por la inmigración asiática así como por el creciente poder militar y económico de Japón. Estos enfrentamientos les permitían exteriorizar subsidiariamente su ansiedad. Es por esta razón que hemos seguido viendo este tipo de combates raciales hasta hoy en día en la lucha profesional. De hecho, los deportes "legítimos" actuales se desarrollan en una atmósfera de sutil y no tan sutil nacionalismo, e incluso de un categórico racismo. Mediante la comprensión de las raíces históricas de los elementos más oscuros de los deportes, los competidores y aficionados modernos podrán ser capaces de superar estos elementos para llegar, simplemente, a disfrutar de las competiciones.

\section{Advertencia sobre la terminología}

A lo largo de este trabajo utilizaremos indistintamente los términos "judo" y "jujutsu", aunque no sean sinónimos. Como argumentaremos detalladamente en la sección I, el judo evolucionó a partir del jujutsu, un proceso que comenzó con la fundación de la academia Kodokan por Jigoro Kano en 1882, y que culminó con el debut del judo como deporte olímpico en los Juegos Olímpicos de verano de Tokio en 1964. Durante este periodo de transición, el judo fue considerado a menudo simplemente como la particularmente efectiva forma del jujutsu practicada por Kano y sus estudiantes, pero no como un arte marcial diferenciada. La mayor parte de jujutsuokas (practicantes de jujutsu) que citamos tienen un linaje que se remonta a Kano, y por tanto no es inexacto calificarlos como judokas. Es más importante, sin embargo, advertir que la más bien mal definida distinción entre el judo y el jujutsu no habría sido comprendida por los periodistas europeo-americanos que produjeron gran parte del material que contienen las fuentes primarias en las que se basa este estudio. No hemos hecho, por tanto, ningún intento de discernir si un atleta en particular se consideraba a sí mismo como estudiante de judo o de jujutsu (Burdick, 1999; Carr, 1993; Shun, 1998).

A pesar de que utilizaremos los términos "judo" y "jujutsu" de un modo más amplio de lo que sería exacto, utilizaremos el término "lucha" de un modo más restringido de lo habitual. El American Heritage Dictionary define la lucha como "[un] deporte en el que dos competidores tratan de lanzar o inmovilizarse mutuamente mediante la lucha cuerpo a cuerpo", lo cual también incluiría al judo y al jujutsu. En este trabajo, "lucha" se referirá únicamente a los estilos de lucha cuerpo a cuerpo de ascendencia europea en los que el objetivo es poner los hombros del oponente sobre el tapiz, más que hacer que el oponente se rinda ("someta") mediante estrangulaciones o manipulaciones articulares, como sucede en las artes marciales inspiradas en el jujutsu. Los estilos de lucha occidentales que satisfacen esta definición también serán tratados detalladamente en la Sección I.

El judo llega a California: Judo vs. Lucha... $\diamond$ Matt Hlinak 


\section{Artes marciales e identidad nacional}

\section{La lucha y la cultura norteamericana}

La lucha en los Estados Unidos evolucionó a partir de diversos estilos de lucha europeos, particularmente de aquellos de origen británico. En los estilos de Cumberland y Westmorland, los competidores cierran sus brazos uno alrededor del otro (una posición conocida por los luchadores modernos como "the clinch" [el cierre]) y el perdedor era el primero al que se le rompiese el agarre. Los luchadores del estilo de Cornwald llevaban chaquetas, que agarraban para obtener ventaja como sucede en el judo moderno. La lucha de Devonshire era similar al estilo de Cornwald, excepto porque también se permitía dar patadas en las espinillas. Uno de los estilos más influyentes era la lucha irlandesa de cuello y codo, en la que los competidores empezaban agarrándose por el cuello y el codo; esta forma de lucha se difundió rápidamente por los estados del norte durante la Guerra Civil debido al gran número de inmigrantes irlandeses que componían las tropas de la unión. Los estilos de lucha franceses, alemanes, holandeses, africanos y nativos de Norteamérica también influyeron en el desarrollo de un estilo de lucha completamente norteamericano (Archer \& Svinth, 2005; Gorn, 1985; Morton \& O'Brien, 1985; Pope, 1997; Savenga, 1995).

La lucha jugó un importante papel en la cultura americana durante el siglo XIX. Este deporte encontró su camino en el "folklore americano desde los primeros días de la República hasta la Guerra Civil" a través de "las historias de las hazañas de sus protagonistas" (Morton \& O'Brien 1985: 19-20). George Washington y Abraham Lincoln fueron considerablemente aclamados por sus habilidades en la lucha cuerpo a cuerpo, y del mismo modo los luchadores estuvieron muy presentes en las obras de Mark Twain. Las competiciones entre soldados durante la Guerra Civil dieron paso a la urbanización pos Guerra Civil y a la estandarización de reglas y técnicas -con algunas resistencias (véase Guttmann, 1994)en un estilo conocido como "catch-as-catch-can" o lucha "catch", que permitía enfrentar a campeones de diversas localidades. Esta estandarización, junto con el fuerte interés en las apuestas, permitió que los luchadores evolucionaran de fornidos hombres rurales a los primeros atletas profesionales de la nación. Mientras que el béisbol crecería para convertirse en el pasatiempo nacional, su desarrollo como deporte profesional se produjo significativamente más tarde respecto al de la lucha en las últimas décadas del siglo XIX. En el punto álgido de popularidad de la lucha, en 1911, más de 35.000 seguidores abarrotaron el Comiskey Park de Chicago para ver el combate de revancha entre Frank Gotch (1878-1917) -"una de las primeras superestrellas atléticas norteamericanas" (Hewitt, 2005: 13-14)- y Georg Hackenschmidt (1878-1968); las entradas para presenciar el acontecimiento llegaron a recaudar 87.000 \$, más de 1,8 millones de los actuales (Betts, 1974; Fielding, 1975; Fielding, 1977; Hewitt, 2005; Rickard, 1999).

Pero la lucha no era simplemente popular en los Estados Unidos; era un empeño netamente americano que resonaba en la cultura fronteriza de los estados del oeste. Numerosos comentaristas describieron el deporte en este periodo de tiempo utilizando el lenguaje de estas tierras fronterizas. Morton \& O'Brien (1985: 9, 20) señalan que los "registros de la expansión norteamericana hacia el oeste están repletos de descripciones de sujetos pendencieros de un solo ojo, posaderos sin orejas y otros que portaban las cicatrices de los combates de pankration ['un tipo de combate sin restricciones que combinaba boxeo y lucha']". Hewitt (2005: 1-2) describe una "violenta tradición de combate largamente asociada a la frontera [en la cual] los habitantes del bosque se enzarzaban habitualmente en peleas donde valía todo". Archer \& Svinth (2005) sitúan en su propia salsa a los luchadores en las zonas esencialmente fronterizas de los "salones, espectáculos del salvaje oeste, circos y teatros de variedades".

Del mismo modo, escritores contemporáneos vieron la lucha como un empeño íntimamente ligado a la cultura americana. Periodistas de la época anterior a la Segunda Guerra Mundial hacían referencia al "bien americano" deporte de la lucha (LAT, 18 de diciembre de 


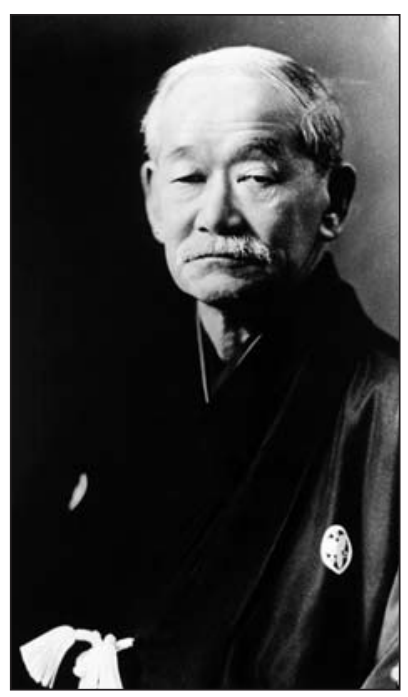

KANO JigORO (1860-1938), FUNDADOR DEL JUDO. Fotografía del Kodokan.

LOS "JAPOS EXPERTOS EN JiU Jitsu” apareCEN en Los Angeles Athletic Club en 1913. Ilustración de Los Angeles Times (7 de abril de 1913).

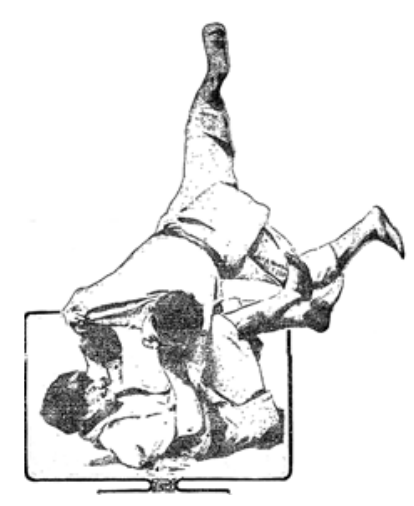

1914), "el método americano del catch-as-catch-can" (OT, 29 de agosto de 1905), o "el plan yanki" de defensa personal (LAT, 4 de marzo de 1905). El "método americano" era un deporte completamente occidental y popular en los Estados Unidos a principios del siglo XX.

\section{El judo y la cultura japonesa}

Todas las culturas del mundo han tenido alguna forma de lucha cuerpo a cuerpo anteriormente a la aparición de los primeros registros históricos, y la cultura japonesa no es una excepción. Las luchas precursoras del jujutsu se desarrollaron en la época medieval como medio de combate de los samuráis que perdían sus espadas. Puesto que las técnicas de golpeo que se encuentran en otras artes marciales asiáticas no eran eficaces frente a un oponente que portaba una pesada armadura, los samuráis crearon un estilo de combate que les permitía inmovilizar al rival con una utilización limitada de puñetazos y patadas. El estilo que actualmente podría reconocer un moderno practicante de jujutsu se configuró durante el siglo XVII. A pesar de que los orígenes del jujutsu pueden situarse en el campo de batalla, fue el largo periodo de paz de los siglos XVII y XVIII el que hizo florecer el jujutsu. En ausencia de guerras, el jujutsu llegó a ser el único medio mediante el cual los miembros de la clase guerrera podían demostrar su masculinidad, particularmente a medida que el gobierno fue erosionando progresivamente los privilegios que una vez tuvieron los samuráis. A medida que el jujutsu se fue divorciando cada vez más de sus orígenes en el campo de batalla, el estilo abandonó muchas técnicas prácticas en favor de otras que eran agradables estéticamente (Burdick, 1997; Carr, 1993).

Durante esta era de paz, el gobierno Tokugawa mantuvo muy aislado a Japón respecto del resto del mundo. En 1853, el comodoro Matthew Perry de la marina de los Estados Unidos amenazó a Japón con una intervención militar si no se abrían los puertos a los buques mercantes norteamericanos. El humillante Tratado de Amistad y Comercio de 1858 puso fin al aislacionismo japonés. Esta brusca "apertura" de la nación isleña perturbó a la sociedad japonesa, provocando tensiones simultáneas y contradictorias tanto hacia la tradición como hacia la modernidad. Muchos japoneses se aferraron a sus costumbres sociales tradicionales, como el jujutsu, contra la invasión cultural americana y europea, a la vez que también se afanaban por adoptar los sistemas económicos y militares occidentales que habían hecho posible el influjo extranjero. Fue con este telón sociopolítico de fondo que Kano Jigoro fundó el Kodokan, su academia de jujutsu en Tokio (Burdick, 1997; Guttmann, 1994; Guttmann \& Thompson, 2001; Rosenblum, 1981).

Kano ejemplifica muy claramente la dicotomía modernista/tradicionalista del Japón de finales del siglo XIX. Nacido dos años antes de la firma del Tratado de Amistad y Comercio, Kano estudió a filósofos occidentales como John Stuart Mill y Herbert Spencer, así como el jujutsu tradicional japonés. Muchas escuelas de artes marciales en este periodo estaban, desde el punto de vista de Kano, demasiado pendientes del ritual y la estética, sin enfatizar suficientemente la practicidad de las técnicas, mientras que otras escuelas habían dado mala fama al jujutsu al haber entrenado a rufianes que lo estudiaban para ser mejores ladrones y luchadores callejeros. Su objetivo fue hacer que el jujutsu fuese más práctico y más noble. En efecto, quería crear un deporte, y esto lo hizo reuniendo aquellas tradiciones que veía útiles y abandonando aquellas que consideraba deficientes (Burdick, 1997; Carr, 1993; Guttmann, 1994; Guttmann \& Thompson, 2001; Kiku, 2004; Shun, 1998; Svinth, 2003).

Kano llamó a su estilo Kodokan judo para distinguir sus métodos de otras formas de jujutsu. El departamento de policía metropolitana de Tokio realizaba periódicamente competiciones de jujutsu, en parte para seleccionar instructores que entrenasen a sus oficiales. Puesto que el Kodokan batió regularmente a los representantes de otras escuelas, la publicidad resultante hizo que el conjunto de estudiantes de Kano creciese de diez estudiantes en 1884 a aproximadamente 500 en 1887, y a unos asombrosos 2.755 en 1892. A medida que los estudiantes de Kano fueron abriendo sus propias escuelas por todo Japón y el resto

$$
\text { El judo llega a California: Judo vs. Lucha... } \quad \diamond \quad \text { Matt Hlinak }
$$


del mundo, la práctica del judo se difundió exponencialmente (Burdick, 1999; Carr, 1993; Shun, 1998).

Sin embargo, el auge del judo no ocurrió en el vacío. Un fuerte movimiento nacionalista se estaba produciendo en Japón. Mientras que Kano no era particularmente conservador, su filosofía de fusionar modernidad y tradición encontró eco en la élite gobernante, que quería utilizar los modernos métodos occidentales para llevar la cultura tradicional japonesa al escenario mundial. En un esfuerzo por distanciarse de algunos de los elementos más burdos que se habían asociado al jujutsu, Kano implementó un código de conducta que reflejaba el bushido de los samuráis. Al mismo tiempo, el gobierno japonés estaba intentando revivir elementos de la cultura samurái con la intención de restaurar el orgullo nacional después del Tratado de Amistad y Comercio. El judo ganó rápidamente el apoyo gubernamental debido a la combinación de su efectividad frente a otras artes y sus valores aparentemente compartidos con las políticas gubernamentales. Hacia 1911, el ministro de educación japonés añadió el judo al currículum nacional de educación física. Muchos japoneses sintieron que el judo era la institución que mejor representaba el alzamiento de Japón desde la humillación al poder en la última mitad del siglo XIX (Burdick, 1999; Guttmann \& Thompson, 2001; Shun, 1998).

Mientras que el judo jugó un papel significativo en la sociedad japonesa durante este periodo, muchos europeo-americanos lo vieron como un elemento prácticamente esencial de la cultura. Los registros contemporáneos norteamericanos estaban llenos de afirmaciones exageradas. Un autor proclamó que toda la nación japonesa, "desde el emperador hasta el culí más humilde" practicaba judo (CRH, 21 de julio de 1904). Incluso entre los inmigrantes, se sentía que "no hay ningún japonés en Los Ángeles que no sepa lo suficiente del arte de defenderse a sí mismo más que satisfactoriamente frente a un hombre que no sea de su propia raza" (LAT, 18 de febrero de 1918). Otro artículo, más bien extravagante, proclamaba que "los duros y pequeños japos, que encarnan la fuerza y que parecen incapaces de fatigarse, a pesar de que su sostenimiento es únicamente unos pocos granos de arroz", y asignaba su resistencia sobrehumana al estudio del jujutsu, que requiere "hábitos diarios" tales como bañarse dos veces al día "si [el jujutsuoka] quisiera imitar a sus profesores japoneses" y beber "un galón [3,78 litros] de agua pura" (SFC, 27 de marzo de 1904). Aunque en estos artículos existiese una buena dosis de exageración periodística, el deporte disfrutó de una gran popularidad entre los japonesesamericanos, que lo seguían como participantes y espectadores (Svinth, 2003).

\section{Visiones europeo-americanas del judo}

Debido al influjo de los inmigrantes japoneses entre 1884 y 1907, los europeos-americanos ganaron interés por la cultura japonesa. Los periódicos en esta época gastaron mucho tiempo explicando el misterioso arte del judo a los blancos. Estos tempranos registros tienden a caer en dos categorías extremas: el rechazo o la admiración. El razonamiento más ridículo de la primera categoría argumentaba simplemente que los europeos-americanos eran cultural y fisiológicamente superiores a los japoneses-americanos, y por tanto los deportes americanos como la lucha y el boxeo debían ser superiores al judo. En un relato representativo, un editorial del Oakland Tribune argumentaba, "un artista completo de catch-as-catch-can sería algo más que un reto para cualquier entusiasta del jujutsu debido a que su ciencia comprende el arte de la protección, que en conjunción con su agresividad americana nativa lo haría prácticamente invulnerable" (OT, 29 de agosto de 1905). Un escritor del Harper's Weekly opinaba que, "el temperamento japonés es indeciso y cambiante dado a bruscas subidas y bajadas", y consideraba que los atletas japoneses poseían "esa notable deficiencia de todos los orientales, la carencia de determinación y perseverancia" (HW, 12 de febrero de 1898). Los Angeles Times declaraba, "no le llevaría mucho tiempo a un hombre medio advertir que un buen boxeador haría que el mejor luchador de judo se pareciese a 20 céntimos de carne para perros" (LAT, 26 de diciembre de 1909). Otro artículo describía el "jew-joot" [jujutsu] como "una farsa de la 


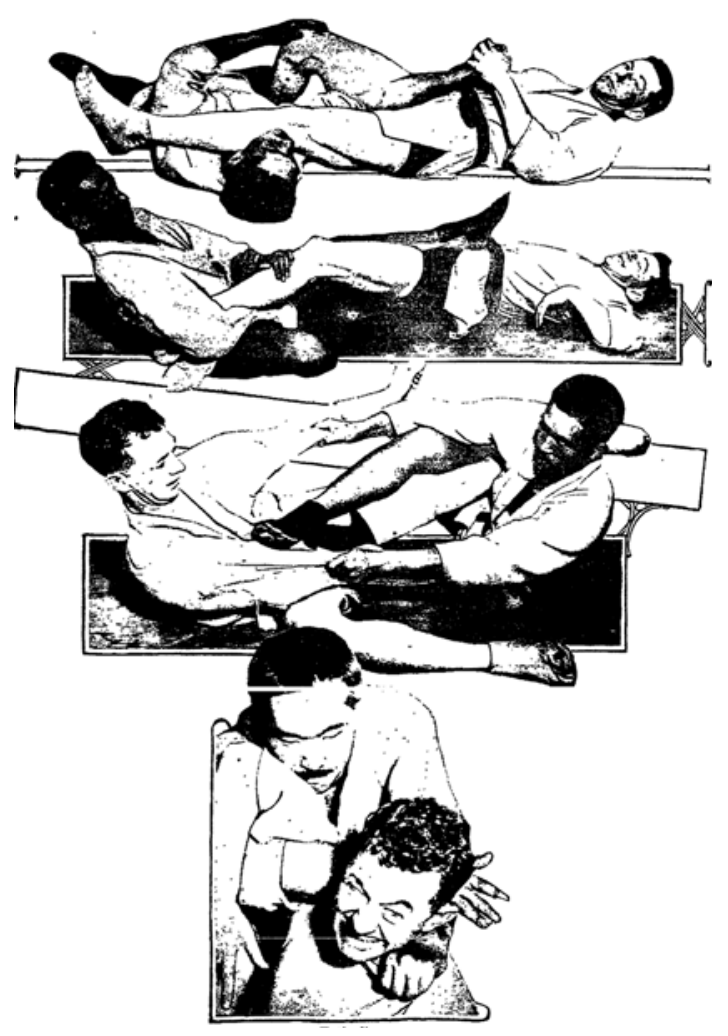

que el pueblo americano debería avergonzarse por enloquecerse con ella, y que cualquier hombre blanco ordinario puede tumbar al tipo marrón [esto es, al japonés]" (LAT, 7 de mayo de 1905). El deletrear la primera sílaba de la palabra jujutsu como "jew" [judío] fue bastante común en los artículos que criticaban el estilo japonés (véase, e.g., MAB, junio de 1905); esto era, presumiblemente, un intento de denigrar la cultura asiática apelando al sentimiento antisemita existente en los Estados Unidos (Burdick, 1999; Wilson, 2000).

Otros escritores en este campo del rechazo al menos basaron sus opiniones en enfrentamientos reales en los cuales los europeosamericanos ganaron a los judokas. En estos casos, los titulares enfatizaban la raza de los competidores más que sus estilos de combate, como por ejemplo "Los cadetes vencen al "japo" (NYT, 21 de febrero de 1905) y "El americano echa al suelo al victorioso japo" (LAT, 4 de marzo de 1905).

Algunos europeos-americanos continuaron rechazando el judo incluso cuando los judokas vencían a los luchadores americanos. Puesto que los deportes occidentales se estandarizaron a finales del siglo XIX, el boxeo y la lucha adoptaron reglas para prevenir las lesiones y ayudar a "civilizar" a los inmigrantes europeos que practicaban estos deportes (Burdick, 1999). El judo permitía la utilización de estrangulaciones y luxaciones, que no estaban permitidas en los estilos occidentales de lucha, de modo que "muchas de las tretas empleadas por los pequeños

Pat Higgins E ITO TOKUGORO EN PLENA PRÁCTICA.

Los Angeles Times (24 de octubre de 1916) hombres marrones serían despreciadas como 'impuras' por nuestros representantes de las artes viriles" (SFC, 16 de octubre de 1904). Los Angeles Times describía el "Judo o negocio de tercer grado" como " cosa basta, pura y simple” (LAT, 26 de diciembre de 1909). Un comentarista sintetizaba las críticas a las técnicas de judo declarando que "cualquier audiencia aficionada al juego limpio las calificaría como faltas y tras la primera intentona serían calificadas como ventajas no leales" (Terry, 1902, citado en Burdick, 1999).

Otros europeo-americanos, incluyendo el presidente Theodore Roosevelt, eran grandes admiradores del judo (Burdick, 1999). Lo que atraía particularmente a la audiencia occidental era el modo en que el judo podía ser utilizado por un hombre más pequeño o incluso por una mujer (véase Svinth, 2000b; Svinth, 2001), para derrotar a un oponente más grande. El Salt Lake Herald señalaba "un pequeño japo versado en los misterios [del judo] puede vencer fácilmente a los atletas más voluminosos que sólo se han entrenado en lucha o boxeo" (SLH, 5 de febrero de 1906). De hecho, "la ciencia del Jiu jitsu enseña al atleta a hacer que la fuerza de su adversario se vuelva contra él, y una vez que el pequeño agarra a su más voluminoso oponente le infringe un gran castigo puesto que éste se resiste y su gran tamaño juega en su contra" (SFC, 17 de diciembre de 1907). Esta habilidad era atribuida al "bien conocido principio mecánico de la palanca", junto con "el obvio resultado de la aplicación de las leyes de la mecánica y de los recursos estratégicos" (LAT, 4 de septiembre de 1904).

Otros comentaristas atribuían la eficacia del judo a las habilidades casi sobrenaturales de sus practicantes. Se decía que los judokas eran capaces de aplicar "toques vitales" sobre los "puntos de la muerte" de los oponentes, cuya localización era un secreto celosamente guardado, para provocar "desde una parálisis temporal del brazo hasta la suspensión completa de los procesos vitales y la muerte instantánea" (LAT, 4 de septiembre de 1904). A un judoka "se le atribuía un modo de mirar al oponente que provocaba todos los síntomas de la plumbosis [envenenamiento por plomo], y algunas de sus grandes victorias se habían logrado a través de la actuación mental" (LAT, 3 de abril de 1919). Existió incluso el temor de que aquellos japoneses-americanos que abrían escuelas de judo escondiesen a sus estudiantes europeo-americanos ciertas técnicas misteriosas que podrían llegar a utilizar en el futuro si se producía un conflicto entre Japón y los Estados Unidos (Burdick, 1999). 
A medida que los inmigrantes japoneses se integraron en la sociedad estadounidense, las competiciones entre judokas japoneses-americanos y luchadores europeo-americanos fueron inevitables. Ambos deportes tenían una fuerte tradición en el mundo del espectáculo. Los luchadores profesionales de esta época eran a menudo empleados de ferias ambulantes que se enfrentaban a los campeones locales cuando el circo viajaba de ciudad en ciudad. Los luchadores estaban, por tanto, predispuestos a desafiar a atletas de otras localidades con el objeto de probar sus habilidades. De un modo similar, la popularidad del judo en Japón se originó por el deseo de Jigoro Kano de probar que su estilo era superior al de otras escuelas de jujutsu. No puede resultar sorprendente por tanto que sus estudiantes participasen en enfrentamientos similares tras emigrar a los Estados Unidos (Burdick, 1999; Carr, 1993; Hewitt, 2005; Morton \& O’Brien, 1985; Shun, 1998).

Los primeros enfrentamientos fueron más o menos no concluyentes, puesto que el luchador solía ser capaz de llevar al suelo y sujetar a su oponente, mientras que el judoka era igualmente capaz de proyectar y someter a su adversario. El resultado dependía, por tanto, de las reglas del deporte que se aplicasen. Los posteriores enfrentamientos se disputaron con sistemas de reglas mixtas, que equilibraron el juego de un modo efectivo. Existieron al menos cuarenta grandes enfrentamientos entre judokas y luchadores que tuvieron lugar entre 1904 y 1920, y casi tres cuartas partes de los mismos tuvo lugar al oeste del río Misisipi. El luchador de catch de San Francisco, Adolph "Ad" Santel (1887-1966) obtuvo un cierto número de victorias sobre judokas, lo que le llevó a proclamarse a sí mismo campeón mundial de judo. El judoka de Seattle Ito Tokugoro ganó la atención de los aficionados europeo-americanos después de apuntarse numerosas victorias sobre destacados luchadores, incluyendo a Eddie Robinson y Ted Thye. Santel e Ito se encontraron dos veces en San Francisco en 1916; Santel ganó el primer enfrentamiento después de que Ito se golpease la cabeza contra el suelo, rindiéndose al no poder continuar (Burdick, 1999; Hewitt, 2005; Svinth, 2003). En la revancha, "Santell [sic] dio un par de gorjeos, se le puso la cara negra y golpeó el suelo, significando que ya había tenido suficiente" tras la estrangulación aplicada por Ito (LAT, 1 de febrero de 1917).

Estos combates mixtos fueron tremendamente populares, obteniendo regularmente una recaudación cada vez mayor y recibiendo una gran atención por parte de los medios, más de la que recibían los enfrentamientos de luchador contra luchador o judoka contra judoka. Particularmente, parece que estos enfrentamientos atraían a los aficionados que apoyaban a los competidores sobre una base racial. Un judoka japonés-americano era vitoreado por "una muchedumbre de alborotadores entusiastas japoneses" (LAT, 9 de diciembre de 1917), mientras que en otro enfrentamiento "los blancos se esforzaban por hacer tanto ruido como los japos, pero los hombres marrones chillaban continuamente" (LAT, 31 de mayo de 1909). En un enfrentamiento, "los blancos" -incluyendo al desvergonzadamente partidario periodista deportivo- "gritaron a favor del blanco, e hicimos todo lo que pudimos para que este ganase, pero los japos nos sobrepasaban en número y nos superaron en entusiasmo" (OT, 2 de abril de 1909). Cuando una solitaria mujer europeo-americano, "una cierta persona de apariencia ordinaria que iba vestida como una dama" -implicando, por supuesto, que tal mujer no sería realmente una "dama"- dio su apoyo al judoka japonés-americano, "provocó los murmullos y los silbidos de la sala, y las cosas que se dijeron de esta joven no quedarían bien por escrito". No todos los aficionados escogían sus lealtades sobre una base racial, pero aquellos que no lo hacían se podían encontrar siendo objeto de hostigamiento por los espectadores, e incluso siendo insultados por los periodistas.

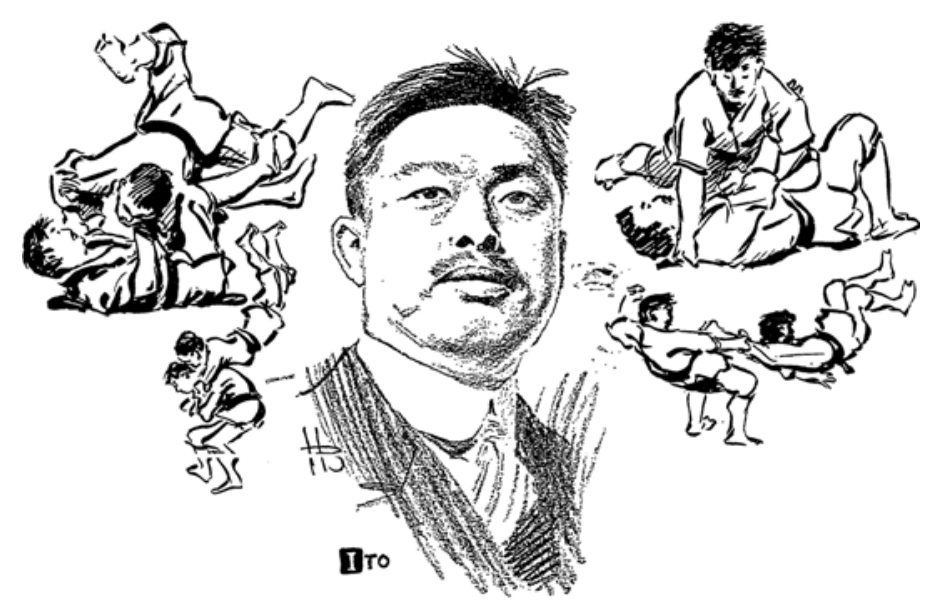




\section{III. ¿Qué atractivo tenían estos enfrentamientos?}

Los europeo-americanos estaban interesados en los combates entre judokas y luchadores por diversos motivos. Uno era el simple interés en la cultura japonesa. Después de todo, hasta hace poco Japón había estado cerrado a los occidentales, y por tanto la exposición al judo suponía una mirada a la sociedad que lo había creado. Pero los europeo-americanos también disfrutaban del modo en que estos enfrentamientos reforzaban los estereotipos sobre los japoneses-americanos. Por ejemplo, la habilidad de un judoka para derrotar a un oponente más grande enfatizaba la supuestamente menor estatura física de los japoneses. De este modo, incluso cuando se alababa la habilidad de un judoka, los periodistas europeo-americanos se referirían desdeñosamente a él como un "pequeño duro japo" (SFC, 27 de marzo de 1904) o un "pequeño caballero marrón" (LAT, 18 de febrero de 1918). Además, algunos periodistas parecían deleitarse al citar, a menudo extensamente, el destartalado inglés de los judokas inmigrantes, con el objeto de presentarlos como menos inteligentes que los hablantes nativos (véase, e.g., LAT, 3 de abril de1919). Los judokas también eran retratados como excesivamente educados, en contraste con los rudos luchadores occidentales, lo cual presentaba nociones de masculinidad en fuerte contraste. Uno es descrito como un "tipo inofensivo", mientras que otro "sonreía y mantenía su buen humor" durante un rudo enfrentamiento (Edgren, 1905). Los respetuosos competidores de judo eran retratados "demostrándose respeto formalmente uno al otro", mientras que cuando "los chicos americanos luchan, lo hacen de un modo improvisado y más bien imprudente, lo cual conmociona al Japo, limitado por las convenciones" (ST, 10 de marzo de 1907). En otra narración, el judogi (uniforme de judo) era referido como "un festivo camisón japonés" y el judoka como "un pendenciero pequeño y descarado" frente a un "blanco fornido" (LAT, 9 de diciembre de 1917). A pesar del resultado del enfrentamiento, al lector no le quedaba duda de quién era el "auténtico hombre" (véase también Sabo, 1985).

Así como la nación-estado moderna es un fenómeno relativamente reciente, también lo es el nacionalismo, que puede ser definido "como una condición de la mente, la sensación o el sentimiento de un grupo de personas que vive en un área geográfica bien definida, que habla un lenguaje común, que posee una literatura en la que se han expresado las aspiraciones de la nación y, en algunos casos, teniendo una religión común" (Snyder, 1990). La otra deplorable cara de la moneda de los buenos sentimientos comunes respecto a otros miembros del estado adopta la forma de racismo y xenofobia hacia aquellos que viven fuera del estado; si el nacionalismo nos infunde la creencia de que nuestra cultura es superior, las otras culturas por tanto deben ser inferiores. Como consecuencia de la Guerra Civil, el nacionalismo norteamericano estaba en su punto álgido. Este nacionalismo a menudo tomó la forma de lo que Billig (1995) denomina "nacionalismo banal", que incluye expresiones rutinarias de sentimiento nacionalista, como por ejemplo la recitación que hacen los niños del Compromiso de Lealtad antes de empezar las clases o la utilización de símbolos patrios en los sellos de correos y en la moneda corriente. El nacionalismo banal encontró expresiones rutinarias en los enfrentamientos deportivos "puesto que la nación estaba 'representada' en la competición a modo de guerra" (McCrone, 1998). Los atletas en la competición internacional encarnan al estado, y sus éxitos y fracasos eran compartidos por sus compatriotas (Betts, 1974; Copeci \& Wilkerson, 1983; Germs, 2006; Guttmann, 1988; Guttman, 1994; Hobsbawn, 1990; Loy \& Elvogue, 1970; Kiku, 2004; Mandell, 1984; Mogull, 1981; Mrozek, 1983; Pope, 1997; Rainville et al., 1978; Schneider \& Eitzen, 1979).

Gran parte del interés europeo y americano en estos enfrentamientos surgió de la ansiedad que provocaba el contexto socio-político general. Los occidentales se sentían amenazados por la inmigración japonesa, que fue eficazmente interrumpida en 1907 mediante

El judo llega a California: Judo vs. Lucha... $\diamond$ Matt Hlinak 
un "acuerdo de caballeros" entre el presidente Roosevelt y el gobierno japonés. Se denegó la ciudadanía a los japoneses-americanos, incluso aquellos de segunda generación, sobre la base del Acto de Nacionalización de 1790, que sólo era aplicado a "personas blancas libres". Más localmente, la Ley Agraria para Extranjeros de California de 1913 prohibía a los asiáticos-americanos la posesión real de propiedades. A pesar de estas restricciones contra los japoneses-americanos, los trabajadores occidentales aún temían el influjo de los peor pagados trabajadores extranjeros. De un modo similar, la victoria de Japón sobre Rusia en 1905, que fue la primera victoria de una potencia asiática sobre un país europeo, dio origen a los miedos respecto al imperialismo japonés (Burdick, 1999; Germs, 2006; Wilson, 2000). De hecho, muchos en Occidente atribuyeron la victoria de Japón al estudio del judo; un escritor fue tan lejos como para recomendar el estudio del jujutsu a los "lectores anglosajones", de tal modo que "las conferencias de paz serán pronto una cosa del pasado" (SFC, 16 de octubre de 1904).

Para comprender cómo estas ansiedades socio-políticas influyeron a los aficionados al deporte durante este periodo, resulta útil consultar los estudios de la moderna lucha profesional, la cual, debe advertirse, es mucho más teatral que los enfrentamientos de principios del siglo XX entre judokas y luchadores (muchos de los cuales eran competiciones atléticas legítimas). Los seguidores de la lucha profesional moderna "son trabajadores de bajo salario, receptores de ayudas sociales o inmigrantes que buscan un pequeño éxito en lo que se supone que es la tierra de las oportunidades" y disfrutan de las emociones indirectas del "entretenimiento deportivo" (Campbell, 1996). Estos grupos están interesados particularmente en historias en las que una "amenaza extranjera", que refleja una amenaza militar o económica real para los Estados Unidos, es derrotada por un héroe americano, que es casi siempre un descendiente europeo. El origen étnico es utilizado a menudo para distinguir los "chicos buenos" de los "chicos malos". Los seguidores europeo-americanos de la lucha anteriores a la Primera Guerra Mundial probablemente hayan sentido unas motivaciones similares, particularmente debido al tenso clima político y económico en el que vivían. Más aún, el hecho de que los enfrentamientos atléticos a los que asistían tuviesen al menos la apariencia de ser legítimos, podría haberles hecho invertir más emoción en el apoyo a su atleta favorito, en contraste con los aficionados modernos que saben que están asistiendo a un "teatro muscular” (Archer \& Svinth, 2005; Mondak, 1989; Deeter-Schmeltz \& Sojka, 2004).

\section{Conclusión}

Los enfrentamientos entre la lucha y el judo en las dos primeras décadas del siglo XX muestran un oeste de los Estados Unidos que estaba a la vez intrigado y atemorizado por los japoneses-americanos y el emergente poder de su país nativo. Gran parte de estos sentimientos se expresaron en un feo nacionalismo, ausente por fortuna en la actualidad -al menos en unos términos tan obvios- en el diálogo político moderno. Pero el nacionalismo, e incluso el racismo, siguen siendo fuerzas conductoras en los deportes modernos, donde muchos de nuestros más cosmopolitas instintos se ven ahogados en el entusiasmo de la batalla. Mediante la comprensión de los orígenes de estas fuerzas podemos lograr la aspiración olímpica de dejar a un lado, realmente, las diferencias culturales en nombre de la competición atlética.

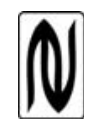




\section{BIBLIOGRAFÍA}

Archer, J. \& Svinth, J. (2005). Professional wrestling: Where sport and theater collide. InYo: Journal of Alternative Perspectives. Disponible en: http://web.archive.org/web 120070818163456/ejmas.com/jalt/jaltframe.htm.

BetTs, J. (1971). Home front, battlefield and sport during the Civil War. Research Quarterly 42: 113-32.

BetTs, J. (1974). America's sporting heritage: 1850-1950. Reading, MA: Addison-Wesley Publishing Co.

Billig, M. (1995). Banal nationalism. London: Sage Publications.

BuRDiCK, D. (1999). The American way of fighting: unarmed defense in the United States, 1845-1945. Doctoral dissertation, Indiana University, Bloomington.

Campbell, J. (1996). Professional wrestling: Why the bad guy wins. Journal of American Culture 19(2): 127-132.

CARR, K. (1993). Making way: War, philosophy and sport in Japanese judo. Journal of Sport History 20(2), 167-188.

CopeCI, D. \& Wilkerson, M. (1983). Multifarious hero. Journal of Sport History 10(3): $5-25$.

Deeter-Schmelz, D. \& SojKA, J. (2004). Wrestling with American values: An exploratory investigation of World Wrestling Entertainment as a product-based subculture. Journal of Consumer Behaviour 4(2): 132-143.

Edgren, R. (1905). The fearful art of jiu jitsu. Outing, 322-28. Reprinted in Svinth, J. (ed.)(2000). Journal of Combative Sport. Disponible en: http://ejmas.com/jcs/jcsart _edgren1_0300.htm.

FieldiNG, L. (1975). Reflections from the sport mirror: selected treatments of Civil War sport. Journal of Sport History 2: 132-144.

Fielding, L. (1977). War and trifles: sport in the shadow of Civil War Army life. Journal of Sport History 4: 151-168.

FILA (2004). History of wrestling. International Wrestling Hall of Fame. Disponible en: http: //www.filahalloffame.com/historyofwrestling.html.

Germs, G. (2006). The athletic crusade: Sport and American cultural imperialism. Lincoln, NE: University of Nebraska Press.

Gorn, E. (1985). "Gouge and bite, pull hair and scratch": The social significance of fighting in the southern backcountry. American Historical Review 90(1): 18-43.

GutTMAnn, A. (1988). A whole new ball game: an interpretation of American sports. Chapel Hill: University of North Carolina Press.

Guttmann, A. (1994). Games and empires: Modern sports and cultural imperialism. New York: Columbia University Press.

Guttmann, A. \& Thompson, L. (2001). Japanese sports: A history. Honolulu: University of Hawai'i Press.

HewitT, M. (2005). Catch wrestling: a wild and wooly look at the early days of pro wrestling in America. Boulder, CO: Paladin Press

Hobsbawn, E. (1990). Nations and nationalism since 1780. Cambridge: Cambridge University Press.

KIKU, K. (2004). The development of sport in Japan: martial arts and baseball. En Dunning, E., et al. (eds.), Sports histories: figurational studies of the development of modern sports (pp. 153-171). New York: Routledge.

Loy, J. \& Elvogue, J. (1970). Racial segregation in American sport. International Review of Sport Sociology 5, 5-23.

Mandell, R. (1984). Sport: A cultural history. New York: Columbia University Press.

Mogull, R. (1981). Racial discrimination in professional sports. Arena Review 5(2): $12-15$

El judo llega a California: Judo vs. Lucha... $\diamond$ Matt Hlinak 
Mondak, J. (1989). The politics of professional wrestling. Journal of Popular Culture 23(2): 139-149.

Morton, G. \& O’Brien, G. (1985). Wrestling to rasslin': Ancient sport to American spectacle. Bowling Green, OH: Bowling Green State University Popular Press.

Mrozek, D. (1983). Sport and American mentality, 1880-1910. Knoxville: University of Tennessee Press.

PoPE, S. (1997). Patriotic games: sporting traditions in the American imagination, 1876-1926. Oxford, UK: Oxford University Press.

RaINVILLE, R. ET AL. (1978). Recognition of covert racial prejudice. Journalism Quarterly 55(2): 256-259.

RICKARD, J. (1999). "The spectacle of excess": The emergence of modern professional wrestling in the United States and Australia. Journal of Popular Culture 33(1): 129. 137.

Rosenblum, M. (1981). Martial arts poetics. Journal of American Culture 4(3): 148-153.

SABO, D. (1985). Sport, patriarchy, and male identity. Arena Review 9(2): 1-30.

SAvenGa, D. (1995). The problem of wrestling 'styles' in the modern Olympic Games: A failure of Olympic philosophy. Citius, Altius, Fortius (actualmente Journal of Olympic Sport History) 3(3): 19-29.

Schneider, J. \& Eitzen, D. (1979). Racial discrimination in American sports. Journal of Sport Behavior 2(3), 136-142.

Shun, I. (1998). The invention of the martial arts: Kano Jigoro and Kodokan judo. En S. Vlastos (ed.), Mirror of modernity: Invented traditions of modern Japan (pp. 163-173). Berkeley, CA: University of California Press.

Snyder, L. (1990). Encyclopedia of nationalism. New York: Paragon House.

SvinTH, J. (2000a). Sizing 'em up: statistical relationships between various combative sports in the Japanese American communities of the Pacific Northwest, circa 1910 to circa 1942. In Yo: Journal of Alternate Perspectives. Disponible en: http://ejmas. com /jalt/jaltart_svinth1_0300.htm.

SVinTH, J. (2000b). Women who would not be sheep. In Yo: Journal of Alternate Perspectives. Disponible en: http://ejmas.com/jalt/jaltart_svinth4_1199.htm.

SvinTH, J. (2001). The evolution of women's judo, 1900-1945. In Yo: Journal of Alternate Perspectives. Disponible en: http://ejmas.com/jalt/jaltart_svinth_0201.htm.

Svinth, J. (2003). Getting a grip: Judo in the Nikkei communities of the Pacific Northwest, 1900-1950. Guelph, Ontario: Electronic Journals of Martial Arts and Science.

TERRY, T. (1902). Jiu-jutsu, Japanese self-defense without weapons. Outing 41, 12-18.

WiLson, G. (Ed.)(2000). The history of Japanese immigration. Brown Quarterly 3(4). Available: http://brownvboard.org/brwnqurt/03-4/03-4a.htm.

\begin{tabular}{llll} 
Periódicos & Abreviatura & Periódicos & Abreviatura \\
\hline Chicago Record-Herald & CRH & Oakland Tribune & OT \\
Harper's Weekly & HW & Salt Lake Herald & SLH \\
Los Angeles Times & LAT & San Francisco Call & SFC \\
Mind and Body & MAB & Seattle Times & ST \\
New York Times & NY & &
\end{tabular}

